


\section{La prensa habanera: refugio de los intelectuales desterrados durante la Revolución Mexicana, 1910-1920}

\section{The Havana Press: a refuge for the intellectuals exiled during the Mexican Revolution, 1910-1920}

Salvador García

Universidad de Miami, Estados Unidos

Resumen: El presente trabajo tiene como principal objetivo bosquejar la labor de los intelectuales desterrados durante la Revolución Mexicana en las revistas culturales y los periódicos cubanos más representativos de la segunda década del siglo XX. Se trata de un tema apenas analizado en los estudios históricos y siempre desde su aspecto político. Basado en el rescate de textos hasta la fecha desconocidos, se reconstruye el itinerario de los escritores nacionales en los medios habaneros durante los momentos más álgidos de la lucha armada. En un primer apartado, el trabajo ofrece un panorama general de los exiliados en Cuba, para posteriormente enfocarse en las figuras de Federico Gamboa y Luis G. Urbina.

Palabras clave: Revolución Mexicana, exilio, Cuba, Gamboa, Urbina.

Abstract: The main objective of this article is to sketch the work published in the most representative Cuban cultural journals and newspapers of the second decade of the 20th century by the Mexican intellectuals who were exiled in Havana during the Mexican Revolution. Historical studies do not approach often to this topic, and when they do is always from a political point of view. The itinerary of national writers in Havana's media, during the fiercest times of the armed struggle, is reconstructed here thanks to the rescue of texts previously unknown. In 
the first section, the article offers a general outllook of the exiles in Cuba, to later focus on the figures of Federico Gamboa and Luis G. Urbina.

Keywords: Mexican Revolution, Exile, Cuba, Gamboa, Urbina.

Recibido: 23 de febrero 2018 Aceptado: 12 de abril de 2018

\section{El destierro en el Caribe}

I a Revolución Mexicana es un hito vivo. Luego de un siglo _continúan sus ecos en todos y cada uno de los ámbitos del país. Desde las esferas políticas hasta las culturales y desde los imaginarios populares hasta las luchas sociales, pueden identificarse las iconografías, los discursos y hasta algunas de las mismas demandas que nutrieron el movimiento armado iniciado, en noviembre de 1910, por Francisco I. Madero en contra del régimen de Porfirio Díaz. La complejidad de los hechos, la violencia de las acciones, la ambivalencia de los personajes involucrados y la duración de una guerra civil que, en su etapa más cruenta, alcanzó una década de enfrentamientos, son otros de los alicientes para la vitalidad de los sucesos revolucionarios que marcaron la entrada de México al siglo XX. Una entrada tan brutal como definitiva.

La nación nunca fue la misma luego del triunfo de los revolucionarios. Se trató no sólo de un cambio político, sino de una modificación profunda en la estructura nacional. Tal vez por primera vez desde su fundación como país independiente, al arribo de las huestes revolucionarias México pudo mirar su verdadero rostro, apenas maquillado por la "pax porfiriana": desigualdad, pobreza, abusos, combinados con hambre, odio y deseos de venganza. Composición que provocó la pugna entre diversos grupos y personajes durante la revuelta. Madero fue el primero en sufrir el ataque lo mismo de porfiristas que de revolucionarios. A su muerte, tras 
la Decena Trágica de febrero de 1913, no se apaciguó el conflicto. Al contrario, se avivó tanto en el norte como en el sur e incluso en el extranjero.

En medio de los vaivenes políticos del lapso que va de 1910 a 1920 empezó el exilio de los mexicanos caídos en desgracia. Ya fuera por pertenecer a la élite porfirista o por haber participado en alguna de las facciones derrotadas, la ruta de los desterrados casi siempre fue la misma. Embarcar en Veracruz rumbo a Estados Unidos, Europa o Cuba. Hacia La Habana, junto a Díaz, primero salieron los personajes más allegados a su gobierno. Familias poderosas que prefiguraban la orgía de muerte en que se convertiría la Revolución. Le siguieron los integrantes del círculo más cercano a Madero. Posteriormente quienes se habían aliado al usurpador Victoriano Huerta y, ya en la etapa constitucionalista, "arribaron los villistas y zapatistas, que eran obligados a abandonar [Cuba] por los carrancistas que finalmente se consolidaban en el poder" (González, 2011: 21).

Entre la nómina de los desterrados destaca el grupo de los hombres de letras. Principalmente abogados o con conocimientos afines que ostentaban una formación profesional en la que, en mayor o menor medida, mostraron intereses literarios. Más allá de compartir ideario, en ese momento lo que los unía era haberse decidido por un grupo derrotado. Para los más desdichados, su intelecto a merced de los intereses políticos los llevó a tener que huir del país por varios años para salvar la vida. Varios de ellos no fueron vistos con buenos ojos ni por otros refugiados ni por residentes de las ciudades a las que llegaban, principalmente en el Caribe. Al aura de sospecha implícita en los extranjeros se le sumaba ser representantes de "un modelo del elitismo y la opresión, de la dependencia y de la hispanofilia, de la represión selectiva y sistemática, y del despotismo permanente" (Morales, 2010: 243). 
Como foco primordial de los desterrados, San Antonio, Texas, fue el territorio que acogió a quienes huían de la revuelta. En esta ciudad se elaboraron frentes de reacción contra lo sucedido en el país. El poco éxito de los proyectos militares y políticos o simplemente el hartazgo de los acontecimientos nacionales, así como la urgencia de recursos económicos llevó a varios de los mexicanos a buscar nuevas tierras, con mejores oportunidades que los Estados Unidos, para sobrevivir el ostracismo. De inmediato la ciudad de La Habana se vislumbró como la mejor opción para los intelectuales. El idioma, los nexos culturales y la hermandad que se había forjado desde la época de La Colonia hacían de Cuba un lugar propicio para los connacionales. En temas prácticos, el puerto habanero era un foco primordial entre las rutas marítimas de Europa, Sudamérica y Estados Unidos, por lo que antes que aislamiento estarían en un sitio donde coincidía el mundo. Además, la cercanía con Veracruz les permitía estar atentos a los acontecimientos, siempre cambiantes, de la guerra en el país, con el propósito de emprender el regreso al terruño si las condiciones mejoraban. "El conjunto de esos factores permitieron la llegada de mexicanos al puerto de La Habana en varios momentos y bajo diversas condiciones y circunstancias" (González, 2014). La perla del Caribe se percibía de esta manera como la mejor de las opciones para los desterrados nacionales. A pesar de las ventajas de Cuba, "la vida les resultó difícil a los exiliados. Salvo contadas excepciones, no hicieron fortuna ni tuvieron empleos bien remunerados" (Ramírez, 2002: 249).

Entre los más afortunados, sin llegar a gozar de opulencias económicas, se encuentra Alfonso E. Bravo, gerente de la compañía teatral Virginia Fábregas y uno de los primeros refugiados mexicanos en afincarse en La Habana, quien en un artículo de 1911 para la revista Bohemia expresa el dolor por la flagelación de su patria. Desde su percepción, se trata de una pelea que enfrenta a mexi- 
canos contra mexicanos, que azuza los peores sentimientos entre connacionales y que secuestra el futuro. Al mismo tiempo, Bravo agradece a esa tierra que le ha dado la bienvenida y que le ofrece un hogar para él y su familia:

México, patria mía. Lejos de ti recuerdo cuán hermosa eres, con tu espléndido cielo azul, con tus mujeres hermosas, con tus caudalosos ríos, tus poblados bosques... con tantos encantos, en fin, con que ha dotado la Naturaleza!

Ahora sufres por los horrores de la lucha entablada entre tus hijos, y los que lejos de ti estamos, sufrimos también. [...] ¡Cuba hermosa! ¡Cuba hospitalaria! Te amo también porque eres bella, porque eres hermana de mi patria. [Aquí] me encuentro entre hermanos, porque en este privilegiado país al mexicano se le quiere y se le considera como a todo extranjero. Decir cubano, es decir hombre hospitalario, franco, alegre, simpático, culto (Bravo, 1911: 393).

Pese al momento crítico que vivía La Isla en ese momento -no tenía ni 20 años como país independiente, se encontraba en un proceso político también álgido y el imperialismo estadounidense le mostraba su brazo opresor-, en un principio el recibimiento de los desterrados presumió una cordialidad sincera. A la hermandad histórica se le sumaba el trabajo hecho por la administración mexicana. Desde el inicio de su dictadura, Porfirio Díaz había emprendido un programa para mejorar la pésima imagen del país, luego de un siglo diecinueve permeado por las guerras fratricidas y las derrotas ante fuerzas invasoras. En diversos medios de prensa se enfocó en vender, a Europa y a los Estados Unidos, la idea de un México en paz y con sed de progreso. La instalación de firmas extranjeras en el país durante el porfirismo demuestra el éxito de su plan publicitario en estos medios. El mismo esfuerzo lo hizo con Cuba, persiguiendo sus sueños de extensión territorial, pero 
alimentando un ideario bolivariano ante la amenaza yanqui y demostrando la valía del país en las artes y en la cultura:

A la par de los objetivos concretos destinados a la proyección económica del país, también los hubo políticos y culturales que fueron considerados como parte del programa. Ofrecer otra idea de México fue esencial en la política exterior mexicana. La proyección del país se acompañó de una prolija producción literaria encargada de ahondar en el tema de la prosperidad nacional descrita por Humboldt en su Ensayo político sobre el Reino de Nueva España (Espinosa, 2011: 19).

Cuando inicia el exilio de los mexicanos en Cuba, los medios dan su espaldarazo a los desterrados. Un año antes, en 1910, la prensa habanera había cubierto ampliamente la celebración del Centenario de la Independencia de México. Número a número, en los diarios y en las revistas de la Isla, se dio cuenta de lo acontecido en la fiesta celebrada por Porfirio Díaz, con la que demostraba el arribo a la Modernidad de su proyecto de nación. Para Cuba, por lo menos en los medios de comunicación, México se percibía como un ejemplo de buen gobierno. Es por ello que al llegar el dictador al puerto, abatido por el derrumbe de su poder, desde las páginas de los periódicos conservadores más importantes de $\mathrm{La}$ Habana, periodistas, escritores y editorialistas no dudan en rendirle pleitesía, a la par que reprochan al pueblo mexicano el abandono de su líder. El 6 de junio de 1911, el Diario de la Marina halaga al político que ha parado en el puerto en su camino a Francia:

El general don Porfirio Díaz, el héroe de Puebla, el fiero león de Oaxaca, el dominador durante más de treinta años de una nación de más de catorce millones de habitantes, aquel cuya voz se oía como la de un oráculo y cuya voluntad se sobreponía a todas las demás voluntades, era uno de tantos pasajeros que venían a bordo del "Ipiranga", sobrecogido todavía por los horrores de una guerra 
cuya pujanza jamás creyera, dominada su alma y torturado su corazón por la ingratitud de un pueblo que había olvidado los grandes beneficios recibidos para fijarse exclusivamente en los errores tal vez involuntarios o en las severidades que se impondrían a veces como necesarias del supremo gobernante (Redacción, 1911: 9).

Si la llegada de Díaz será sentida, no menos destacable es el arribo de la familia de Francisco I. Madero. La postura de la administración cubana de José Miguel Gómez y la actuación de su ministro en México, Manuel Márquez Sterling, durante la Decena Trágica, se destacaron por su apoyo en contra de los golpistas de la Ciudadela: Félix Díaz y Manuel Mondragón. Cada una de sus decisiones los muestran a favor de la concordia antes que la barbarie. Será el diplomático cubano quien duerma junto a Pino Suárez y Madero para evitar que los políticos sean asesinados en esa primera noche de su arresto a manos de Victoriano Huerta. El mismo Márquez Sterling dispondrá en Veracruz del barco, emblemáticamente llamado "Cuba", para salvar a los familiares del presidente caído, como lo presenta el Diario de la Marina en su edición del primero de marzo de 1913:

Creímos presenciaríamos un cuadro de abatimiento supremo.

Y nos sorprendió la entereza, tanto de las mujeres como de los hombres, de aquella familia en desgracia.

Sus rostros reflejaban intenso dolor; mas en todos se admiraba el valor ante la desgracia, la resignación entera. El llanto ha dejado huellas en sus rostros, pero una sombra como de orgullo ante la crueldad de sus enemigos triunfantes, reflejan sus facciones. Ninguno oculta su pena sin abatirse. Parece que sacuden en rebeldía contra la consumación de los tristes hechos.

Las personas de esta familia llegadas en el "Cuba" son:

D. Francisco Madero y su señora, doña Mercedes González, padres del ex Presidente. 
D. Ernesto Madero, tío, quien desempeñaba el cargo de Secretario de Hacienda, y sus dos hijos Ernesto y Luis.

Doña Sara Pérez, viuda del Presidente derrotado.

Doña Rafaela Madero de Zirión, hermana, con sus cuatro hijos: María de la Luz, Mercedes, Antonio y Felipe.

Y las otras dos hermanas del ex Presidente: Mercedes y Ángela.

Mercedes es la bella señorita que al tener noticias de la muerte de su hermano insultó a la escolta de la penitenciaría, llamándolos asesinos y cobardes (Redacción, 1913: 10).

Las notas de El Diario de la Marina muestran una correlación respecto a los hechos en México. Si el dictador fue laureado a su llegada, la familia Madero también es lisonjeada en el mismo sentido. Los textos muestran que la prensa se alineaba según los mandatos del gobierno cubano, pero más precisamente de los propios dueños de los medios. Defendían un discurso pacificador ligado a las causas menos agrestes del momento. Ante la vorágine de la Revolución Mexicana no podían sino tomar posición a favor de civilidad. Cuando llega Huerta al poder, la situación cambia y, con algunas excepciones, el discurso dominante es dictado desde Washington que, desde entonces, no dejaba de agobiar a la Isla.

La ayuda a los exiliados es dada también por Márquez Sterling quien, junto a Orestes Ferrara, les abrirá las puertas a los intelectuales mexicanos -Federico Gamboa, Querido Moheno, Luis G. Urbina, Esteban Maqueo Castellanos, Salvador Díaz Mirón, José María Lozano y Antonio de la Peña y Reyes, entre otros- en sus proyectos editoriales más importantes: El Heraldo de Cuba, La Lucha, La Nación y La Reforma Social. Con tales decisiones a favor de los desterrados, "de 19911 a 1917 el promedio anual de la inmigración mexicana ascendió a 441, cifra que duplica ampliamente la del periodo anterior (1904-1910) cuando dicho promedio fue de 196" (Argüelles, 1989: 118-119). Entre 1914 y 1917 se da el mayor número de exiliados a la Isla, luego de la caída de Huerta y 
durante el agudizamiento de los conflictos entre Carranza, Villa y Zapata. Para 1919 la población mexicana registrada en la Isla era 3,469 pobladores (Argüelles, 1989: 119).

Cuando las distintas facciones empezaron hacer vida en La Habana, la diversidad de ideologías saltó a la plaza pública. Se hacían homenajes a Díaz, mientras que miembros revolucionarios en contra del dictador se iban sumando a los llegados al puerto. La revista Bohemia le rinde culto a "Don Porfirio" cuando se conoce su muerte: "Ha fallecido en París, el General Porfirio Díaz. En realidad había muerto el día que sus pies dejaron de pisar tierra mexicana. [...] era uno de los hombres de más visión y más recio pensar en América” (Redacción, 1915: 319). Por parte de los revolucionarios, Hipólito Villa, hermano del "Centauro del Norte", se radica en la calle San Miguel, número 210, de La Habana, desde donde empieza a hacer política a favor de su causa. Una connacional, avecindada en Cuba, lo recordaba:

era alto y delgado y siempre hablaba inglés con la señora, a la que llamaba Nina. Ella se veía una mujer culta y de muy buenos modales. Tenían con ellos una niña llamada Andrea, que decía que era hija de Pancho Villa. A Nina le gustaba mucho hablar de Pancho Villa, y siempre que iba alguien a visitarlos, le mostraba las fotografías que tenía de él. Era además una mujer confiada (García, 1968: 99).

Mientras la Colonia Mexicana en La Habana crecía en número fueron incrementándose sus acciones casi siempre sociales y culturales, aunque también las hubo políticas. La presencia de literatos mexicanos y del tema México en los medios cubanos abarcó diversos proyectos editoriales. Entre las revistas se puede mencionar a El Fígaro, Social, Avispas, Ideas, El Estudiante, Albores, Cuba en Europa, La Reforma Social, Cuba Contemporánea y Bohemia. En cuanto a los periódicos el impacto revolucionario, con plumas y 
sucesos, se presentó en La Noche, La Prensa, El Mundo y también los ya mencionados Diario de la Marina y El Heraldo de Cuba. Una y otra vez aparece en estos medios el dolor de los desterrados, como lo demuestra el poema "Balada del exilio", de J. Peña Ángel:

Me siento fatigado. Por todos los caminos me di a viajar con mis recuerdos, solo; he sentido la fiebre de los soles andinos y la anemia nerviosa de las lunas de polo.

Me siento fatigado. Con mis fardos eternos crucé por los senderos ańejos y olvidados. ¡Conozco las tristezas de todos los inviernos y sé las tentaciones de todos los pecados!

Hoy quiero descansar: reír como los niños a la sombra del huerto; perseguir los carińos de las aguas traviesas de las claras fontanas;

Dormirme en el regazo silente de las lomas, amar las timideces de todas las palomas y escuchar madrigales de las buenas gitanas (Peña, 1916: 16).

Mientras tanto en el plano social, en 1915, se estableció el Círculo Mexicano (B.L.M.), “de carácter aristocrático, cuyo secretario era Oswaldo de Guerrero" (Argüelles, 1989: 130-131). El tenis Violeta del Cerro se erigió como otro lugar de la sociedad nacional en Cuba, junto al más emblemático de los proyectos denominado El Casino Mexicano, inaugurado el 27 de abril de 1918 y que estaba ubicado en el antiguo edificio "Miramar", entre Malecón y Prado, frente al castillo del Morro. La directiva estuvo compuesta de la siguiente manera: "presidente, Federico Gamboa; vicepresidente, General Guillermo Rubio Navarrete; secretario, señor Ignacio Bravo Betancourt. Como vocales aparecían José María Lozano, 
Francisco Escudero, Salvador Díaz Mirón, Gonzalo Zúñiga, Agustín del Río, Rafael Goyeneche, Manuel Irigoyen Lara, Antonio de la Peña y Reyes, Gonzalo A. Salas y Joaquín Capilla” (Argüelles, 1989: 130-131). Desde la prensa se saludaba al nuevo organismo: "Demás está que hagamos contar que con verdaderas simpatías nos proponemos contribuir al sostenimiento de un Casino que será orgullo de una de las colonias extranjeras más cultas y dignas de respeto con que contamos en La Habana" (Redacción, 1918: 393).

Sin embargo, la cálida acogida que parecía convertirse en una cotidianidad habanera fue nublándose por la Primera Guerra Mundial. Las repercusiones en América provocaron que durara poco el proyecto del Casino Mexicano. Derivado de las investigaciones que Estados Unidos realizaba en la Isla, a fin de detectar influencia alemana tanto en cubanos como en exiliados, al organismo se le acusó de germanofílico. Igual como había ocurrido un año antes con la revista de Francisco Elguero denominada La América Española -órgano de difusión de los mexicanos en el destierro-, el acoso estadounidense en contra de los connacionales en Cuba se dejaba sentir. Había sufrido la misma penuria el abogado Querido Moheno al ser separado de su puesto como redactor en Diario de la Marina, debido a las mismas acusaciones a favor de Alemania. Los mexicanos fueron acusados de espías alemanes, "por lo que se ordenó la clausura de los medios impresos que habían mostrado alguna simpatía hacia los liberales. Entre los periódicos involucrados estuvieron: La Nación, el Heraldo de Cuba y la revista Reforma Social. Incluso, se acusó a Alemania de financiar el movimiento sedicioso en la isla" (González/Mijango, 2014: 51). Desde La Politica Cómica puede observarse la cacería de brujas en contra de los extranjeros que se presumiera actuaban en contra de Los Aliados. Al cierre de El Heraldo de Cuba, de Márquez Sterling, y donde Luis G. Urbina laboraba, se menciona: 
Ha sido suspendida la publicación del Heraldo de Cuba. Lo sentimos por tratarse de un compañero en la prensa; pero no lo podemos llorar por haber a la sombra de él extranjeros que han venido a agitar las pasiones a Cuba, con el poco piadoso propósito de que aquí ocurra lo que en México y Santo Domingo, donde pelean hermanos contra hermanos sin dejas ni los rabos.

Los instantes son preciosos

$y$, pues han dado motivo,

váyanse los perniciosos...

¡cada mochuelo a su olivo! (Redacción, 1917: s/n).

Con la entrada y salida de barcos, la movilidad poblacional de La Habana era un terreno propicio para las conjuras. Desde el puerto cubano Félix Díaz no se cansaba de organizar movimientos a fin de alcanzar el poder de México que veía como un derecho de familia. De la misma manera, en suelo habanero se fraguó una parte de la última aventura de Huerta, con dinero alemán, con el propósito de destronar a Carranza (Benítez, 2016: 209-220). Representantes y allegados de Zapata también tocarían tierra en el Caribe. Aun con el escozor revolucionario dos de los intelectuales mexicanos más importantes que se establecen en Cuba, Federico Gamboa y Luis G. Urbina, mantendrían una sana distancia respecto a los asuntos políticos.

Federico Gamboa, el patriarca de los desterrados

Para el 19 de junio de 1915, cuando llega a bordo del "Buenos Aires", Federico Gamboa es una de las figuras más importantes de las letras latinoamericanas. La fama de Santa lo ubica en el pedestal más alto del Naturalismo en castellano, como bien lo escribe el poeta cubano Ramón R. Gollury, bajo el pseudónimo de Roger de 
Lauria, quien desde Bohemia es el encargado de dar la bienvenida a los huéspedes ilustres de La Isla:

Hombre de cultura excepcional, su labor literaria ha culminado en una novela que ha recorrido triunfalmente el universo, yendo a ocupar sitio de honor al lado de las más famosas de Emilio Zola, el célebre creador de la escuela que en Santa, -tal la novela aludida-, sigue don Federico Gamboa...

Labor verdaderamente excepcional la realizada en esta obra, sin pecar de exagerados nos atreveríamos a afirmar que la heroína mejicana se nos presenta mucho más humana, -pese al ambiente de poesía y de ensueño de que surge aureolada-, que la otra francesa que en la inmortalidad responde por Naná... (De Lauria, 1916: 3).

En el plano político el trabajo del escritor era igualmente reconocido. Su labor diplomática en Centro y Sudamérica, en Estados Unidos y en Europa, lo dotaban de una gran popularidad. Será la misma fama lo que coloque en una situación cuestionable cuando llega Cuba. Como muchos de los intelectuales del siglo XIX mexicano, Gamboa creció en el porfirismo. En el ambiente decimonónico nacional logró sus primeros triunfos literarios, periodísticos y laborales, mientras se dejaba seducir por los placeres, tan dulces como peligrosos, de la bohemia del fin de siglo. Si bien estaba al tanto de los problemas sociales del país, le apostó al orden y al progreso. Fue un convencido de que sólo Don Porfirio Díaz podría hacer de México un país civilizado. Al igual que gran parte de los intelectuales del porfirismo, nunca le perdonó a Madero que hubiera llevado a cabo un movimiento armado para derrocar al dictador. Veía en los revolucionarios a gente bárbara, sin educación, ni principios, maniquíes del imperialismo estadounidense, que llevarían a la nación al despeñadero. Es por eso que, aunque con dudas totalmente justificadas, aceptó el llamado de Victoria- 
no Huerta para integrarse a su gobierno, tal y como lo hicieron Francisco León de la Barra, Antonio de la Peña y Reyes, Querido Moheno, José López Portillo y Rojas, José María Lozano, Nemesio García Naranjo, Carlos Rincón Gallardo, Enrique González Martínez, Luis G. Urbina, Salvador Díaz Mirón, entre otros. Hombres de letras, la mayoría de ellos, que veían en Huerta, no la solución, pero sí una vía para reorganizar la normatividad institucional quebrantada por la Revolución de 1910 .

Apenas un mes y algunos días estuvo Gamboa en el puesto de secretario de Relaciones Exteriores - del 11 de agosto al 24 de septiembre de 1913-, ofrecido por Huerta. Dejó el encargo para competir por la presidencia de la república por el Partido Católico, en fórmula con Eugenio Rascón. Pese a las críticas del novelista en contra de los Estados Unidos, la presidencia de Woodrow Wilson no veía mal la postulación de Gamboa. La percepción positiva del candidato católico era compartida por la élite porfiriana. Los embates llegaron entonces desde la prensa por parte del medio literario. Díaz Mirón lo atacó en las páginas de El Imparcial llamándolo "el ex comulgado, el masón, el soberano príncipe rosacruz, el caballero del águila y del pelícano, el pornógrafo novelista” (Gamboa, 1994: 134). Mismo tono que utilizaría el peruano Santos Chocano en la carta abierta que se publica en el diario habanero de $\mathrm{La}$ Noche, cuando se conoció el involucramiento del novelista en los asuntos políticos de México:

Comenzaré por manifestarle que no tengo a Huerta y Blanquet por hombres -llamémoslos así- más peligrosos que de la Barra y Usted; porque si Huerta y Blanquet proceden por ambición mezclada con cinismo, de la Barra y usted proceden con ambición mezclada con hipocresía. Más repugnantes aún que los pretorianos que infestan todavía algunas de nuestras enfermas repúblicas son los hombres civiles que arquean ante tales pretorianos los hu- 
mildes lomos y los escoltan o corean, lacayunamente apretados dentro de sus libretas diplomáticas (Chocano, 1913: 7).

Frente a tales cuestionamientos y el ardid de Huerta para invalidar el proceso electoral el 9 de diciembre, Gamboa queda mal parado política y socialmente (Mac Gregor, 2015: 286). Tras una breve estancia en Estados Unidos, llega abatido a La Habana. Por el peso de su nombre funge como una figura patriarcal de los exiliados mexicanos en La Isla, pero su primera preocupación será obtener recursos para mantener a su esposa e hijo, que lo acompañan, así como enviar alguna ayuda a su familia dejada en el país. Rechaza involucrarse en asuntos políticos más allá de intervenir a favor de alguno de los desterrados, siempre y cuando sea necesaria su injerencia. Con la pluma en la mano se aboca a vivir de la literatura. Nada sencillo le resultaría el objetivo en Cuba, pues a los medios que lo pueden acoger, como Diario de la Marina, El Heraldo de Cuba o El Fígaro, Gamboa exige remuneración acorde a su fama. Remuneración con la que no estaban de acuerdo los editores. Cuando aparece su nombre en algún medio es casi siempre como una aclaración de alguna infamia o una reseña solicitada por el autor del libro abordado, como en el caso de Bohemia donde analiza El retablo de Maese Pedro, de Emilio Gaspar, autor conservador que se lanza contra la ciencia y el arte que alimentan el ateísmo (Gamboa, 1917: 25).

Es en La Reforma Social (revista mensual de cuestiones sociales, económicas, politicas, parlamentarias, estadísticas y de higiene pública), donde el novelista encontró acomodo. Por el pago de 100 dólares mensuales -lo que le permitía sufragar sus gastos más inmediatos-, Gamboa tenía que fungir como director interino ante las ausencias de Orestes Ferrara, dueño de la publicación. Además, formaba números completos y se hacía cargo de las reseñas aparecidas número a número. Su labor más importante era la de publicar artículos propios, con lo que la revista se veía beneficiada. En las páginas de 
su nuevo hogar literario Gamboa abre sus intervenciones con " $\mathrm{La}$ novela mexicana", conferencia que había ofrecido en el Ateneo de la Juventud a su regreso al país en 1913. En el texto hace un recuento del género, desde Egipto y la India, para llegar al Virreinato de la Nueva España y, por último, a los autores decimonónicos y de principios del siglo XX, sus contemporáneos. La conclusión del texto refleja la perspectiva de Gamboa, todavía alimentada con un matiz de esperanza. Si bien el ambiente nacional no era propicio para las letras nacionales, vendrían nuevos tiempos donde, como la realidad mexicana, la literatura podría gozar de dichas y sosiego:

Hoy por hoy, la novela apenas si se permite levantar la voz. Muda y sobrecogida de espanto, contempla la tragedia nacional que hace más de tres años nos devasta y aniquila. Hasta su casa solariega llegan los resplandores del incendio matricida, al ayear de los que mueren y los entrecortados sollozos de la ciudad y huérfanos que claman al cielo por la inmensa desdicha que los aflige.

La novela, de luto ya, como el país entero, recordando pasadas calamidades, conociendo la vitalidad increíble de esta tierra adolescente y mártir; confía y espera. Confía, en que Dios se apiade de nosotros; en que los hombres recobren la razón; en que loa Abeles y los Caínes, mutuamente se perdonen (Gamboa, 1915: 28).

Tras su primera publicación donde, como puede leerse, quiso estérilmente alejarse de las cuestiones políticas, Gamboa publicaría el cuento "Atrio" y los ensayos "Maximiliano y Miramón frente al Cadalso", "Porfirio Díaz en 1901” y "La responsabilidad del presidente Wilson en México". Presentó de la misma manera cuatro entregas de La confesión de un palacio, novela que terminó en Cuba y cuyos avances quedaron truncados al terminar su trabajo en la publicación. Alentó asimismo el tema de México en la revista. El venezolano Jacinto López, el mismo Ferrara y Manuel Márquez 
Sterling, quien ofreció un fragmento de su libro Los últimos días del presidente Madero, tomaron parte en el debate respecto a la situación del país. Gamboa abrió La Reforma Social a las colaboraciones de sus connacionales Victoriano Salado Álvarez y Antonio de la Peńa y Reyes. El primero ofreció el ensayo titulado "La independencia de Tejas y la esclavitud" y, el segundo, "Cuauhtémoc, monarca azteca", un adelanto de la obra que publicaría en La Habana con el título Diccionario biográfico mexicano.

La participación de Federico Gamboa en la revista fue de julio de 1915 a febrero de 1917, cuando los brotes rebeldes en La Isla son la constante y las autoridades, azuzadas por el gobierno estadounidense, empiezan a cerrar medios acusados de liarse con los alemanes o atentar contra el gobierno cubano. Meses después, Orestes Ferrara se muda a Nueva York y desde allá continúa su proyecto editorial, pero ya sin la ayuda de Gamboa, quien vivirá limitado con trabajos administrativos y traducciones para otros medios, como el de Francisco Helguero. Por las penurias, por la incapacidad de volver a México, por los problemas de salud de su esposa que finalmente regresaría antes al país, Gamboa padece los últimos dos años vividos en La Habana. Con una depresión zigzagueante, pasa los días hasta que el 8 de octubre de 1919, a bordo del "Venezuela", se embarca rumbo a Veracruz. En Cuba -dirá en sus memorias-, "encanecí de cuerpo y alma" (Gamboa, 1994: 628).

\section{Luis G. Urbina frente al malecón}

En los primeros días de marzo 1915, Luis G. Urbina llega a La Habana, acompañado de los reconocidos músicos Manuel M. Ponce y Pedro Valdés Fraga, yerno de Juan de Dios Peza. Los primeros días tienen que pasarlos en Lazareto de Mariel, en ese momento acondicionado como campamento de inmigración. Pese a las circunstancias, poco propicias para la literatura, una vez que tocó tierra 
el poeta empieza su fascinación por La Isla. Frente al Caribe, con los azules que parpadean en verde, escribe "El poema de Mariel", dedicado a los pescadores con los que había entablado amistad. El "Viejecito", como era comúnmente conocido en la república de las letras, llegaba con una reputación bien ganada como poeta, antes que como político, exentándolo de los conflictos que se daban en La Habana en torno a las figuras de Díaz, Madero, Huerta y, a partir de 1914, de Villa y Zapata que empezaron a ganar relevancia en las páginas de los diarios cubanos.

La suerte de los migrantes mexicanos hizo que el compositor y escritor habanero Eduardo Sánchez de Fuentes fungiera como su mecenas. El mismo personaje ayudaría posteriormente a Salvador Díaz Mirón, José María Lozano, Pedro Valdez Fragua y Francisco M. Olaguíbel. A fin de solucionar las necesidades de manutención, Sánchez de Fuentes organizó una presentación de los mexicanos en la Sala Espadero del Conservatorio Nacional de Música de Hubert de Blank. Mientras Urbina recitaba versos, Ponce mostraba sus composiciones y Valdés Fraga hacía lo propio en el violín. Como el trabajo estable tardaba en aparecer, los exiliados también fueron colocados por otros amigos habaneros para dar clases particulares a niños y jóvenes. Luis Sánchez, uno de los alumnos e hijo del mecenas, recuerda:

Al tener conocimiento de la llegada de aquellos Tres Reyes Magos, esta vez sobre las gibas de las olas, los intelectuales cubanos se movilizaron para ponerse en contacto con ellos, unos por conocer el poeta insigne, al compositor famoso y al violinista notable, y otros con el noble propósito de encontrarles una manera decorosa de hacer frente a sus naturales privaciones de exiliados. De este último grupo formó parte, desde los primeros momentos, mi padre, quien fuera desde entonces un infatigable mantenedor de las glorias y un amigo entrañable hasta la muerte, de aquellos visitantes en desgracia. Justo es reconocer que Urbina y Ponce 
formaron con mi padre un triunvirato que jamás dejó de estar en contacto, aunque las distancias se interpusieran entre ellos (Sánchez de Fuentes, 1957: 155).

Viviendo en la casa de huéspedes Martínez House, ubicada en la esquina de Prado y Virtudes, Urbina y Ponce se trasladaban los domingos hasta la residencia de Sánchez de Fuentes, quien les tenía preparado un buen festín con el que aminoraban la nostalgia de fin de semana. Para la sobremesa jugaban póker donde se les unía Leopoldo Kiel, un técnico también mexicano encargado de la creación de las Escuelas Normales en Cuba y, quien en el corro de intelectuales, conformaba el cuarteto habanero. Los sufrimientos del destierro los iban aminorando entre amigos. Esa camaradería, como tabla de salvación, se ve reflejada en el apartado "La vida a bordo", del poemario El glosario de la vida vulgar, que Urbina dedica a "Manuel, Eduardo y Leopoldo":

No cantan las olas; parece que gimen: y cuando en la calma solemne del mar, los flancos del buque golpean y oprimen, parece que ansía llorar.

En la gran llanura, negra y cristalina, se extiende una blanca senda de esplendor, por donde mi sueño camina, camina, en busca del último amor.

Por sobre cubierta para un marinero, Lo escucho en voz baja cantar. Yo miro los astros, diciéndoles: "Quiero ser como vosotros: ver el mundo entero, por ver solamente mi hogar".

La luna en creciente cual vaso de acero, colgada del clavo de luz de un lucero, alumbra la enorme tristeza del mar (Urbina, 1916a: 133). 
La popularidad del poeta hace que su actividad literaria no cese. Está presente en las tertulias de Antonio Médiz Bolio y es invitado, junto a Agustín Acosta, a los festejos literarios de Camajuaní, en la provincia de Villa Clara, en noviembre de 1915. En el lugar recita sus versos que fueron muy celebrados por los asistentes al evento. De la misma manera se relaciona con José María Chacón y Calvo, presidente del Ateneo de La Habana, y participa en el homenaje que se le brinda a Juan Clemente Zeneapor en el aniversario luctuoso número 44 de cuando fue fusilado en la lucha por la Independencia de Cuba. Urbina es invitado por Piedad Zenea de Bobadilla, hija del poeta fallecido, y en la ceremonia comparte con el ya mítico Aniceto Valdivia, Conde Kostia. En la crónica del evento para Bohemia, escribe Guillermo de Sanz:

Agigantados por la inmortalidad, los árboles sembrados, y apenas erguidos en el gran marco del horizonte, brotaron flores de los labios de tres grandes de la literatura: Enrique José Varona dijo que la gloria del poeta y Conde Kostia y Urbina desgranaron sus versos... y frases y versos fueron como un canto que sirvió de epílogo al poema preparado tan espiritualmente por una hija bien amada (De Sanz, 1916: 102).

Sus contactos le abrieron las puertas de El Heraldo de Cuba, de Márquez Sterling, donde fungió como redactor y colaboró con diversos textos, entre ellos, las crónicas de La Habana que un año después publicaría en España con el título de Bajo el sol y frente al mar. En estos textos se registran los temas que siempre le inquietaron a Urbina, desde el crimen hasta la prostitución, y desde las afectaciones de la psiquis hasta la contemplación de la naturaleza. No sin rasgos románticos, dibuja aquellas tardes de domingo en que, junto a sus amigos, paseaba por las calles habaneras y, sobre todo, sus caminatas por el malecón, una obra de ingeniería que nunca dejó de seducirle al mexicano: "Como muchos desocu- 
pados, como muchos tristes, busco brisa, consuelo y recreo en la orilla del mar, en el Malecón. Y algunas veces encuentro todo lo que busco; pero una de las tres cosas, siempre la encuentro: el recreo de la mirada, el cuadro de la inmensidad arriba y abajo. Nada hay comparable a la riqueza de estos crepúsculos" (Urbina, 1916b: 118-119). Como corolario de su influencia en la prensa habanera, es parte de una encuesta del El Fígaro, realizada a quienes se consideraban los mejores autores en Cuba. A la pregunta “¿Cómo hace usted sus versos?", el poeta responde:

Para escribir, en general, necesito hallarme en un estado psíquico distinto del ordinario, y por lo mismo un poco molesto en los primeros instantes. Este estado se caracteriza por la concentración de energías hacia el mundo interior. Necesito ver mucho para adentro y abrir de par en par la memoria. Porque el recuerdo es el factor más importante en mis operaciones mentales en el instante en que tengo la necesidad de exteriorizar mi espíritu por medio de la palabra "castigada" y pulida. Para mí "hacer literatura", en particular, "hacer versos", es algo fisiológicamente doloroso, porque es algo anormal (Urbina, 1915a: 769).

No obstante la vitalidad de la vida literaria en La Habana, "el Viejecito" sufría los efectos del destierro. Le preocupaba tanto el porvenir como la familia que dejó en México. Especialmente le conmovía la salud de su mujer Lucecita. El talante de Urbina se avecindaba a la desdicha, tal y como lo describe Horacio Blanco Fombona en la estampa que le dedica al mexicano en El Fígaro:

Su actitud, más que discreta, es huraña. Siempre lo hallo con un irremplazable gesto de amargura. Y siempre a idéntica pregunta la idéntica respuesta: ¿Y ese gesto, poeta: qué le pasa? —Desde que salí de México no he vuelto a saber de mi familia-. No sólo la ignorancia de lo que ha pasado en su hogar, desde que lo abandonó, hace meses, por primera vez en la vida; contribuye también a su 
amargura, la prolongada convulsión de su patria; ya que Urbina es, en política, más bien conservador. No cree en la eficacia de las revoluciones. Opina que no valen éstas todo lo que destruyen (Blanco, 1915: 535).

Acongojado por la falta de noticias de su esposa, Urbina hacía todo lo posible por allegar recursos económicos para poder enviar dinero a Lucecita, quien finalmente lo alcanza en Cuba en 1916. Para mejor comodidad del matrimonio, el poeta decidió mudarse a un segundo piso de la calle de San Rafael, entre Águila y Galiano. Hasta el nuevo hogar llegaron amigos - mexicanos y cubanos- a conocer a Lucecita cuyas afectaciones de salud se recrudecieron por el viaje al Caribe. La intranquilidad de la situación se refleja en los textos que el mexicano publica en la misma revista bajo el título "Poemas inéditos":

En medio del bochorno de la siesta, Yo me pregunto: - ¿qué obsesión es ésta, en la que inquieto y angustiado vivo? Hace tiempo que escribo, escribo, escribo, $Y$ nadie me contesta.

— Q Que ha llegado el vapor! Viene el cartero; saluda a mi puerta en los umbrales; me da libros, periódicos, postales... ¡y no me da as cartas que yo quiero! todos, al verle, se apresuran; giran en torno de la gran bolsa de cuero, preguntan: - ¿tango cartas?- y suspiran; las reciben, sonríen, y me miran; yo espero, espero, espero... los huéspedes, leyendo, se retiran y se marcha el cartero.

- ¿Qué obsesión sería ésta en la que, en sombra y soledad, me ahogo? 
Interrogo, interrogo;

Pero nadie contesta (Urbina, 1915b: 535).

En El Fígaro se publicará también el prólogo que Víctor $\mathrm{Mu}$ ñosz escribió para Bajo el sol y frente al mar, editado un año después. Ya fuera de La Habana, Urbina sigue apareciendo en la publicación, al igual que otros mexicanos, ya exiliados, ya visitantes de paso, ya figuras oficiales, como Julio Torri, Alfonso Reyes, José Juan Tablada, Enrique González Martínez, Balbino Dávalos, Pedro Enríquez Ureña, Rafael Heliodoro Valle, José Vasconcelos, y los representantes del gobierno carrancista: Félix F. Palavicini que se ostenta como secretario de Instrucción Pública; Gabriel Alfaro, jefe de la legación mexicana en Cuba en 1919, y Manuel García Jurado, cónsul de México en La Habana. Lugar aparte merece Amado Nervo, la figura nacional más reconocida y con más presencia en los medios habaneros de la época, a quien El Fígaro le dedica el número 43 de 1919, cuando sus restos llegan a La Habana provenientes de Uruguay.

En 1916, Urbina consigue que El Heraldo de Cuba lo mande a España como corresponsal, en medio del conflicto bélico que azotaba a Europa. Como puede leerse en los párrafos anteriores, su involucramiento en medios habaneros no cesó en los siguientes años. Además de El Fígaro, parte de su obra parece en Social, otro refugio para la literatura mexicana del momento. Urbina comparte la publicación con Enrique Uhthoff, Jaime Tió Pérez, el mismo Amado Nervo, José Peón del Valle, José Juan Tablada, Rafael Heliodoro Valle, Efrén Rebolledo y José Santos Chocano, que no es mexicano pero que le dedica unos versos a Pancho Villa.

Entre publicación y publicación, sorteando los avatares del exilio, fue cómo los desterrados intelectuales de nuestro país fueron desarrollando una labor destacable en la prensa cubana entre 1910 y 1920 (González/Mijango, 2014: 45), contribuyendo con artículos, poemas, ensayos y narrativa que forman parte de su ideario 
político o de un acervo literario hasta la fecha desconocido. Se trata de un exilio esperando a ser rescatado de ese olvido oficial tan recurrente para las facciones derrotadas de nuestra historia nacional.

\section{Bibliografía}

Argüelles Espinasa, Luis Ángel, 1989, "Los refugiados mexicanos en Cuba (1910-1927)", La Palabra y el Hombre, núm. 70, México, abril-junio, pp. 117-148.

Benítez, Fernando, 2016, Lázaro Cárdenas y la Revolución mexicana. I El porfirismo, FCE, México.

Blanco Fombona, Horacio, 1915, "Con Urbina”, El Fígaro, año 11, núm. 32, La Habana, 10 de octubre, p. 535.

Bravo, Alfonso E., 1911, "Nostalgia e impresiones", Bohemia, año 2, núm. 40, La Habana, 1 de octubre, p. 393.

Chocano, José Santos, 1913, "El problemático sucesor de Huerta: carta abierta a Federico Gamboa", La Noche, La Habana, 12 de octubre, p. 7.

De Lauria, Roger, 1916, "Huéspedes ilustres", Bohemia, año 7 , núm. 31, La Habana, 30 de julio, p. 3.

De Sanz, Guillermo, 1916, “Zenea”, Bohemia, año 6, núm. 35, La Habana, 30 de julio, p. 102.

Espinosa Blas, Margarita, 2011, "La proyección de México en Cuba: la estela del artilugio 1886-1910", Tzintzun: Revista de estudios históricos, Instituto de Investigaciones José María Luis Mora, núm. 54, México, julio-diciembre, pp. 13-52.

Gamboa, Federico, 1915, "La novela mexicana", La Reforma Social, vol. 5, La Habana, agosto-noviembre, pp. 3-28.

, 1917, "Emilio Gaspar Rodríguez y El retablo del Maese Pedro", Bohemia, año 8, núm. 26, La Habana, 1 de julio, p. 25. 
, 1994, Mi diario VI, Conaculta, Memorias mexicanas, México.

García Alonso, Aida, 1968, Manuela la mexicana, Ediciones Casa de las Américas, La Habana.

González Gómez, Claudia, 2011, "Resucitar el Porfiriato: impresiones del periodista cubano Mario Guiral Moreno", en México y el Caribe: visiones y reflexiones, UAQ/UMSNH/CIALC/ UNAM, México, pp. 15-28.

González Gómez, Claudia, 2014, "El medio de expresión de los exiliados de la Revolución Mexicana: América Española”, en Cuba y México. Visiones desde la prensa y la opinión pública 1900-1917, UMSNH, México, pp. 66-67.

GonzálezGómez, Claudia, y Eduardo Mijango Díaz, 2014,"Alertas de los exiliados mexicanos sobre la participación de Cuba en la Primera Guerra Mundial”, en Cuba y México. Visiones desde la prensa y la opinión pública 1900-1917, UMSNH, México, pp. 43-64.

Mac Gregor, Josefina, 2015, Del porfiriato a la Revolución, Colmex, México, pp. 509.

Morales Pérez, Salvador E., 2010, "La Habana: centro de exilio y confrontaciones durante la Revolución Mexicana", en Impacto de la Revolución Mexicana, Siglo XXI, México, 227-254.

Peña, J. Ángel, 1916, "Balada del exilio", Bohemia, año 7, núm. 3, La Habana, 16 de enero, p. 16.

Ramírez Rancaño, Mario, 2002, La reacción mexicana y su exilio durante la Revolución de 1910, Miguel Ángel Porrúa, México.

Redacción, 1911, "El General Don Porfirio Díaz en La Habana”, Diario de la Marina, La Habana, 4 de junio, p. 9.

, 1913, "Crónicas del puerto", Diario de la Marina, La Habana, 1 de marzo, p. 10. 
, 1915, "Actualidades", Bohemia, año 6, núm. 28, La Habana, 11 de julio, p. 319.

, 1917, "Actualidades", año 12, La Política Cómica, núm. 584, 18 de febrero, s/n.

, 1918, "Notas de actualidad", año 9, Bohemia, núm. 18, La Habana, 5 de mayo, p. 393.

Sánchez de Fuentes Sell, Luis, 1957, "La intimidad de Luis G. Urbina. Memorias de un discípulo", Revista de la Biblioteca Nacional de Cuba José Martí, núm. 2, La Habana, enero-diciembre, pp. 153-180.

Urbina, Luis G., 1915a, “¿Cómo hace usted sus versos?”, El Figaro, año 21, núm. 47, La Habana, 28 de noviembre, p. 769. , 1915b, "Poema inéditos”, El Fígaro, año 21, núm. 41, La Habana, 10 de octubre, p. 535.

, 1916a, El glosario de la vida vulgar, Imprenta de M. García y Galos Sáez, Madrid.

, 1916b, Bajo el sol y frente al mar, Imprenta de M. García y Galos Sáez, Madrid. 